\author{
B.I. Kuznetsov, T.B. Nikitina, I.V. Bovdui, B.B. Kobilyanskiy
}

\title{
IMPROVING OF ELECTROMECHANICAL STABILIZATION SYSTEMS ACCURACY
}

\begin{abstract}
Aim. Improving of accuracy parameters and reducing of sensitivity to changes of plant parameters for nonlinear robust tank main armament guidance and stabilization electromechanical systems based on synchronous motor with permanent magnets and vector control. Methodology. The method of multiobjective synthesis of nonlinear robust control by nonlinear tank main armament stabilization electromechanical system taking into account the elastic oscillations of the tank gun barrel as a discretecontinuous plant and with parametric uncertainty based on the multiobjective optimization. The target vector of robust control choice by solving the corresponding multicriterion nonlinear programming problem in which the calculation of the vectors of the objective function and constraints is algorithmic and associated with synthesis of nonlinear robust controllers and modeling of the synthesized system for various modes of operation of the system, with different input signals and for various values of the plant parameters. Synthesis of nonlinear robust controllers and non-linear robust observers reduces to solving the system of Hamilton-Jacobi-Isaacs equations. Results. The results of the synthesis of a nonlinear robust tank main armament guidance and stabilization electromechanical systems are presented. Comparison of the dynamic characteristics of the synthesized tank main armament stabilization electromechanical systems showed that the use of synthesized nonlinear robust controllers allowed to improve the accuracy parameters and reduce the sensitivity of the system to changes of plant parameters in comparison with the existing system. Originality. For the first time carried out the multiobjective synthesis of nonlinear robust tank main armament stabilization electromechanical systems. Practical value. Practical recommendations are given on reasonable choice of the gain matrix for the nonlinear feedbacks of the regulator and the nonlinear observer of the tank main armament stabilization electromechanical systems, which allows improving the dynamic characteristics and reducing the sensitivity of the system to plant parameters changing in comparison with the existing system. References 24, figures 1.
\end{abstract}

Key words: tank main armament guidance and stabilization electromechanical systems, nonlinear robust control, multiobjective synthesis, dynamic characteristics.

Цель. Повыщение параметров точности и уменьщение чувствительности к изменениям параметров объекта управления нелинейной робастной электромеханической системы наведения и стабилизации танкового вооружения на основе синхронного двигателя с постоянными магнитами и векторного управления. Методология. Метод многокритериального синтеза нелинейных робастных регуляторов для управления нелинейной электромеханической системой стабилизации танкового вооружения с учетом упругих колебаний ствола танковой пушки как дискретноконтинуального объекта управления с параметрической неопределенностью основан на выборе вектора цели робастного управления путем решения соответствующей задачи многокритериального нелинейного программирования, в которой вычисление векторов целевой функции и ограничений носит алгоритмический характер и связано с синтезом нелинейных робастных регуляторов и моделированием синтезированной системы для различных режимов работы системы, при различных входных сигналах и для различных значений параметров объекта управления. Синтез нелинейных робастных регуляторов и нелинейных робастных наблюдателей сводится к решению системы уравнений Гамильтона-Якоби-Айзекса. Результаты. Приводятся результаты синтеза нелинейной робастной электромеханической системы наведения и стабилизации танкового вооружения. Сравнение динамических характеристик синтезированной электромеханической системы наведения и стабилизации танкового вооружения показало, что применение синтезированных нелинейных робастных регуляторов позволяет повысить параметры точности и снизить чувствительность системы к изменению параметров объекта управления по сравнению с существующей системой. Оригинальность. Впервые проведен многокритериальный синтез нелинейной робастной электромеханической системы наведения и стабилизации танкового вооружения. Практическая ценность. Приводятся практические рекомендации по обоснованному выбору матриц коэффициентов усиления нелинейных обратных связей регулятора и нелинейного наблюдателя электромеханической системы стабилизации танкового вооружсния, что позволяет улучшить динамические характеристики и снизить чувствительность системы к изменению параметров объекта управления по сравнению с существующей системой. Библ. 24 , рис. 1 .

Ключевые слова: электромеханической системы наведения и стабилизации танкового вооружения, нелинейная робастное управление, многокритериальный синтез, динамические характеристики.

Introduction. Ukraine is a tank country, which has plants for the production and repair of tanks and tank equipment. Ukrainian tanks have rather high tactical technical characteristics and are well bought by many foreign countries [1]. Most tanks of the Ukrainian armed forces are T-64 tanks which was developed in the $60 \mathrm{~s}$ and which need to be modernized. Ukrainian «Bulat» T-64BM tank is the result of a deep modernization of the T-64 tank [2]. It was developed by the A.A. Morozov Kharkiv Machine Building Design Bureau. The upgraded «Bulat» T-64BM tank is equipped with a modern command and control system with a livelihood that provides the shooting of the gunner and the commander with a high probability falling from the first shot [2]. It should be noted that the cost of the «Oplot» tank production is equivalent to the cost of upgrading ten T-64 tanks to the «Bulat» T-64BM tank level [3]; therefore, the modernization of T-64 tanks is also reasonable from an economic point of view.

The basis of combat in modern conditions is shooting on the move at high speed and maneuverability of tank movement [1,2], therefore all modern tanks of the world are equipped with stabilizers of tank armament, which allow to conduct aimed fire on the move [4-8]. The likelihood of fire damage to the target at maximum speeds of movement, high maneuverability and effective engagement of the tank from the fire damage of the

(c) B.I. Kuznetsov, T.B. Nikitina, I.V. Bovdui, B.B. Kobilyanskiy 
enemy is largely determined by the accuracy of maintaining a given direction of tank weapons on the target with intense disturbing influences from the tank hull $[1,2]$. Therefore, the issues of further improving the accuracy of stabilization of main tank armament are a real problem, both in the development of new systems of tank weapons and in the modernization of existing systems that are in use [1-3].

One of the areas of modernization of the T-64 tank is to improve the accuracy of control of the main armament to increase the likelihood of target destruction. The guidance and stabilization system for the main armament of the T-64 tank contains a DC electric drive with an electric machine power amplifier in the azimuth (turret) axis of the tank turret and an electro-hydraulic drive of the tank gun in the in the elevation (gun) axis [1]. To improve the accuracy of controlling the main armament of «Leopard» 2A5/6, «Merkava» Mk-3, «Abrams» M1 tanks modern AC electric drives are being developed to replace existing electro-hydraulic and DC electric drives [10]. The «VNII «Signal»« scientific and industrial production unit developed and conducted experimental studies of 2E58 Electric Gun and Turret Drive Stabilization System with AC electric drive based on a synchronous motor with permanent magnets (PMSM) and vector control (VC) to replace existing DC drives and electro-hydraulic drives of main tank armament guidance and stabilization systems [11, 12]. Such an AC electric drive allows for higher speeds and accelerations of the tank turret and gun compared with existing electro-hydraulic drives and DC drives to improve the accuracy of the guidance and stabilization system. Experimental studies of such AC electric drives for controlling the turret and gun of the T-72 tank made it possible to improve the transfer speed by up to 1.5 times (up to 45 degrees/sec) and also to improve the smoothness of the drives at low speeds [10].

Note that the American firm «HR Textron», the Israeli firm «Elbit» based on the developed system for the «Merkava» Mk3 tank, the European concern «EADS» and others offer a fully electric guidance and stabilization system (Electric Gun and Turret Drive Stabilization System) by the main armament for the modernization of Ukrainian tanks [10].

As numerous tests and analysis of test results have shown, that the accuracy of firing on the move is significantly affected by the tank gun barrel elastic oscillations $[2,8]$. «Bulat» T-64BM tank gun 2A46-2 barrel undamped oscillations frequency experimentally determined and is equal $10.14 \mathrm{~Hz}$ [8], which holds back the improve by the tank tower and gun guidance and stabilization systems accuracy.

Mathematical model of the tank gun as a plant, taking into account the gun barrel elastic oscillations as a discrete-continuous plant developed in the [8]. The gun barrel is considered as an elastic beam in the form of a distributed load, rigidly fixed in the breech. But this model does not take into account the turret imbalance, which leads to the removal of the turret with gun from the target direction. Note that the Ukrainian tanks turret unbalance moment reaches $40 \mathrm{kN} \cdot m$ against $1-1.5 \mathrm{kN} \cdot \mathrm{m}$ at the foreign tanks turret [11].
The problem of parametric synthesis of guidance and stabilization systems, taking into account the elasticity of the tank gun barrel also is given in the [8]. However, these systems use the classical structure of regulators with feedbacks from electric angle gyros sensor and electric rate gyros sensor on the gun in the elevation (gun) axis and the turret in the azimuth (turret) axis, which limits the possibilities of obtaining high accuracy of the system.

On the other hand, the emergence of modern micro gyros and high-speed computing means allows us to reduce the weight and dimensions of the control system and implement more complex control algorithm.

The goal of this work is to improve of the accuracy parameters and reduce of sensitivity to changes of plant parameters for electromechanical tank armament stabilization systems with synchronous motor with permanent magnets and vector control based on multiobjective synthesis of nonlinear robust control.

Problem statement. Consider the mathematical models of the electromechanical gun stabilization system taking into account the gun barrel elastic elements oscillations as a discrete-continuous plant [8]. Model consists of an elevation (gun) axis model and an azimuth (turret) axis model. Imagine a gun model in the form of a solid body and an elastic element. In addition to rotation relative to the axis, the gun performs elastic oscillations. Denote by the $\varphi(t)$ - elevation angle and $\psi(t)$ - azimuth angle of gun and turret rotation as the solid body, $y_{G}(x, t)$ and $y_{T}(x, t)$ - the deviation of the points of the rod from its undeformed state in elevation and azimuth axes. For the gun and turret dynamics, the torques applied to the solid body equals the actuator torques $T_{A G}(t), T_{A T}(t)$ plus the disturbance torques $T_{D G}(t), T_{D T}(t)$ acting on the gun and turret, minus the turnnion friction torques. $T_{F G}(t), T_{F T}(t)$. The disturbance torques $T_{D G}(t), T_{D T}(t)$ acts relative to the elevation and azimuth axes of rotation of gun and turret as solid body, and the distributed forces $F_{0 G}(x, t), F_{0 T}(x, t)$ acts along the length of the tank gun barrel as elastic element in elevation and azimuth axes.

The equations of plant movement relative to its elevation and azimuth axes of rotation can be written as follows

$$
\begin{aligned}
& J_{0 G} \frac{d^{2} \varphi(t)}{d t^{2}}(t)-\int_{r}^{r+l} m_{1}(x) \frac{\partial^{2} y_{G}(x, t)}{\partial t^{2}} d x=T_{A G}(t)+ \\
& +T_{D G}(t)-T_{F G}(t) ; \\
& J_{0 T} \frac{d^{2} \psi(t)}{d t^{2}}(t)-\int_{r}^{r+l} m_{1}(x) \frac{\partial^{2} y_{T}(x, t)}{\partial t^{2}} d x=T_{A T}(t)+ \\
& +T_{D T}(t)-T_{F T}(t),
\end{aligned}
$$

where $J_{0 G}, J_{0 T}-$ moment of inertia of gun and turret as the solid body relative to the elevation and azimuth rotation axes; $m_{1}(x)$ - the mass of the rod, which is connected with the running weight of the $\operatorname{rod} m(x)$ in the ratio $m_{1}(x)=m(x)(x+r)$, in which $r-$ the distance of the point of attachment of the rod to the axis of the gun gate.

This equations (1), (2) describes the free movement of the electromechanical system as a discrete-continuous plant, in which $J_{0 G}, J_{0 T}$ has the characterization of the 
electromechanical system as a solid body, and $m_{1}(x)$ characterizes the mutual influence of the motion of the solid body and the oscillations of the elastic bar as a plant mechanical part with distributed parameters. The functions $y_{G}(x, t), y_{T}(x, t)$ in (1), (2) satisfies of the elastic beam oscillation equations

$$
\begin{aligned}
& m_{1}(x) \frac{d^{2} \varphi(t)}{d^{2} t}+m(x) \frac{\partial^{2} y_{G}(x, t)}{\partial t^{2}}+E I(x) \frac{\partial^{4} y_{G}(x, t)}{\partial x^{4}}+ \\
& +\xi E I(x) \frac{\partial^{5} y_{G}(x, t)}{\partial x^{4} \partial t}=F_{0 G}(x, t) ; \\
& m_{1}(x) \frac{d^{2} \psi(t)}{d^{2} t}+m(x) \frac{\partial^{2} y_{T}(x, t)}{\partial t^{2}}+E I(x) \frac{\partial^{4} y_{T}(x, t)}{\partial x^{4}}+ \\
& +\xi E I(x) \frac{\partial^{5} y_{T}(x, t)}{\partial x^{4} \partial t}=F_{0 T}(x, t),
\end{aligned}
$$

where $E I(x)$ and $\xi$ - tank gun barrel distributed rigidity and internal damping coefficient; $F_{0 G}(x, t), F_{0 T}(x, t)-$ external disturbance distributed over the tank gun barrel due to hull oscillations in elevation and azimuth axes.

We represent in equation (3), (4) the functions $y_{G}(x, t), y_{T}(x, t)$ in the form of the following series

$$
\begin{gathered}
y_{G}(x, t)=\sum_{i=1}^{n} \gamma_{i_{G}}(x) W_{i G}(t) \\
y_{T}(x, t)=\sum_{i=1}^{n} \gamma_{i T}(x) W_{i T}(t),
\end{gathered}
$$

where $n$ - the number of forms of plant elastic oscillations taken into account.

The equations obtained from (1)-(6) describe the motion of an electromechanical system as a discretecontinuous plant under the action of an actuator torques $T_{A G}(t), T_{A T}(t)$, disturbance torques $T_{D G}(t), T_{D T}(t)$, turning friction torques $T_{F G}(t), T_{F T}(t)$, as well as the length distribution of the tank gun barrel of external perturbations $F_{0 G}(x, t), F_{0 T}(x, t)$ which is due to hull oscillations in elevation and azimuth axes;

$$
\begin{aligned}
& J_{0 G} \frac{d^{2} \varphi(t)}{d t^{2}}-\sum_{i=1}^{n} \frac{d^{2} W_{i G}(t)}{d t^{2}} \int_{r}^{r+l} m_{1}(x) \gamma_{i G}(x) d x= \\
& =T_{A G}(t)+T_{D G}(t)-T_{F G}(t) ; \\
& J_{0 T} \frac{d^{2} \psi(t)}{d t^{2}}-\sum_{i=1}^{n} \frac{d^{2} W_{i T}(t)}{d t^{2}} \int_{r}^{r+l} m_{1}(x) \gamma_{i T}(x) d x= \\
& =T_{A T}(t)+T_{D T}(t)-T_{F T}(t) ; \\
& \quad m_{1}(x) \frac{d^{2} \varphi(t)}{d t^{2}}+m(x) \sum_{i=1}^{n} \gamma_{i G}(x) \frac{d^{2} W_{i G}(t)}{d t^{2}}+ \\
& ++E I(x) \sum_{i=1}^{n} \frac{\partial^{4} \gamma_{i G}(x)}{\partial x^{4}} W_{i G}(t)+ \\
& +\xi E I(x) \sum_{i=1}^{n} \frac{\partial^{4} \gamma_{i G}(x)}{\partial x^{4}} \frac{d W_{i G}(x)}{d t}=F_{0 G}(x, t) ;
\end{aligned}
$$

$$
\begin{aligned}
& m_{1}(x) \frac{d^{2} \psi(t)}{d t^{2}}+m(x) \sum_{i=1}^{n} \gamma_{i T}(x) \frac{d^{2} W_{i T}(t)}{d t^{2}}+E I(x) \sum_{i=1}^{n} \frac{\partial^{4} \gamma_{i T}(x)}{\partial x^{4}} \ldots \\
& \ldots W_{i T}(t)+\xi E I(x) \sum_{i=1}^{n} \frac{\partial^{4} \gamma_{i T}(x)}{\partial x^{4}} \frac{d W_{i T}(x)}{d t}=F_{0 T}(x, t) .
\end{aligned}
$$

The control precision is largely determined only by the first form of tank gun barrel elastic oscillation. Taking into account only the first basic form of elastic oscillations in expression (5), (6) the function is represented

$$
\begin{aligned}
& y_{G}(x, t)=\gamma_{0 G}(x) W_{0 G}(t) \\
& y_{T}(x, t)=\gamma_{0 T}(x) W_{0 T}(t) .
\end{aligned}
$$

Then the equations of the dynamics of the electromechanical system as a discrete-continuous plant (7)-(12) in elevation and azimuth axes will take the following form

$$
\begin{gathered}
J_{0 G} \frac{d^{2} \varphi(t)}{d t^{2}}-a_{0 G} \frac{d^{2} W_{0 G}(t)}{d t^{2}}=T_{A G}(t)+T_{D G}(t)-T_{F G}(t) ; \\
J_{0 T} \frac{d^{2} \psi(t)}{d t^{2}}-a_{0 T} \frac{d^{2} W_{0 T}(t)}{d t^{2}}=T_{A T}(t)+T_{D T}(t)-T_{F T}(t) ; \\
a_{0 G} \frac{d^{2} \varphi(t)}{d t^{2}}+c_{0 G} \frac{d^{2} W_{0 G}(t)}{d t^{2}}+\xi_{G} b_{0 G} \frac{d W_{0 G}(t)}{d t}+\ldots \\
+b_{0 G} W_{0 G}(t)=f_{0 G}(t) ; \\
a_{0 T} \frac{d^{2} \psi(t)}{d t^{2}}+c_{0 T} \frac{d^{2} W_{0 T}(t)}{d t^{2}}+\xi_{T} b_{0 T} \frac{d W_{0 T}(t)}{d t}+\ldots \\
+b_{0 T} W_{0 T}(t)=f_{0 T}(t) .
\end{gathered}
$$

Coefficients $a_{0 G}, a_{0 T}, c_{0 G}, c_{0 T}$ and $b_{0 G}, b_{0 T}$ in equations (13)-(15) are obtained by substituting expression (5), (6) into equation (8), (9) multiplying both parts of the resulting equation by $\gamma_{0 G}(x), \gamma_{0 T}(x)$ and integrating both parts of the equation in the range from $r$ to $(r+l)$.

In the elevation and azimuth axes there are two types of external disturbance. The first type of external disturbance is related to the hull longitudinal angular oscillations. These disturbances cause a disturbance torques that acts on the gun and turret

$$
\begin{aligned}
& M_{D G}=\mu_{0} \frac{d \varphi_{H}(t)}{d t} ; \\
& M_{D T}=\mu_{0} \frac{d \psi_{H}(t)}{d t},
\end{aligned}
$$

where $\mu_{0}-$ constant coefficient, which is determined experimentally; $d \varphi_{H}(t) / d t$ and $d \psi_{H}(t) / d t-$ hull angular rate in elevation and azimuth axes.

The second type of external perturbation is associated with hull accelerations relative to its elevation axis. These accelerations, being annexed to the distributed masses of the gun, cause its elastic fluctuations. Distributed forces applied to the gun and turret and included in the equation of its elastic oscillations are determined by the following dependencies

$$
\begin{aligned}
& F_{0 G}(x, t)=m(x) \frac{d^{2} z_{G}(t)}{d t^{2}} ; \\
& F_{0 T}(x, t)=m(x) \frac{d^{2} z_{T}(t)}{d t^{2}},
\end{aligned}
$$


where $m(x)$ - the weight of the gun elastic part; $d^{2} z_{G}(t) / d t^{2}$ and $d^{2} z_{T}(t) / d t^{2}$ - hull acceleration relative to its elevation and azimuth axes. Then we will get

$$
\begin{gathered}
f_{0 G}(t)=\frac{d^{2} z_{G}(t)}{d t^{2}} \int_{r}^{r+l} m(x) \gamma_{1 G}(x) d x=k_{z G} \frac{d^{2} z_{G}(t)}{d t^{2}} \\
f_{0 T}(t)=\frac{d^{2} z_{T}(t)}{d t^{2}} \int_{r}^{r+l} m(x) \gamma_{1 T}(x) d x=k_{z T} \frac{d^{2} z_{T}(t)}{d t^{2}} .
\end{gathered}
$$

External perturbations acting on the hull in the elevation and azimuth axes are to a large extent determined by the longitudinal angles and hull vertical and horizontal fluctuations. Note that using equations (16), (18) and (20), disturbing moments due to the tank turret imbalance are also taken into account. Using equations (15), (17) and (19), disturbing moments due to the tank gun imbalance are also taken into account.

With direct torque control (DTC) by a synchronous motors with permanent magnets (PMSM) [13] actuator torques $T_{A G}(t), T_{A T}(t)$ motion equations can be written as follows $[14,15]$

$$
\begin{aligned}
& \tau \frac{d T_{A G}(t)}{d t}+T_{A G}(t)=K_{A G} U_{A G}(t) ; \\
& \tau \frac{d T_{A T}(t)}{d t}+T_{A T}(t)=K_{A T} U_{A T}(t),
\end{aligned}
$$

where $U_{A G}(t), U_{A T}(t)$ - inputs control, $\tau$ - equivalent constant times and $K_{A G}, K_{A T}-$ contour gains of DTC.

Method of synthesis. Let us write down the original turret and gun model (13) - (22) of the electromechanical system as a discrete-continuous plant taking into account the moles of the executive motors (23), (24), hull suspension effects and sensors as plant of robust control system with a state vector $x(t)$ in the standard form of a state equation

$$
\frac{d x(t)}{d t}=f(x(t), u(t), \omega(t), \eta(t)),
$$

where $u(t)$ is the control, $\omega(t)$ and $\eta(t)$ are the vectors of the external signal and parametric perturbations, $f-$ is a nonlinear function.

The mathematical model (25) takes into account the nonlinear frictional dependencies on the shafts of the drive motor, the rotating parts of the reducer and the gun and turret, the gear gap between the teeth of the driving and driven gears, the constraints for control, current, torque and motor rate, as well as the plant moment of inertia.

In particular, the model of turnnion friction torques $T_{F}(t)$ of drive motor, reducer and plant adopted in the following form[7]:

$$
T_{F}=\left\{\begin{array}{l}
T, \text { if }|T| \leq T_{s} \text { and }|\omega|<0.001 ; \\
\left(T_{k}+\left(T_{S}-T_{k}\right) \cdot e^{-\left(\omega / \omega_{s}\right)^{\delta}}\right) \cdot \operatorname{sign}(\omega)+v \cdot \omega, \text { if }|\omega| \geq 0.001,
\end{array}\right.
$$

where $T_{F}$ - the moment of friction; $T$ - the moment applied to the shaft that is cracking; $T_{s}-$ moment of friction of rest (static friction); $T_{k}$ - the moment of kinetic friction.
Measured output vector of the initial system

$$
y(t)=Y(x(t), \omega(t), u(t))
$$

is formed by different sensors which measured the angular, rate and acceleration of turret, gun and hull in elevation and azimuth axes and placed at the turret, gun and at the hull [7].

The task of synthesis is the determination of such a regulator $[16,17]$ which, based on the measured output (26) forming control $u(t)$ using a dynamic system described by the difference state equation and output

$$
\begin{gathered}
\frac{d \xi(t)}{d t}=f(\xi(t), u(t), \omega(t), \eta(t))+\sum_{i=1}^{3} G_{i}(y(t)- \\
-Y(\xi(\mathrm{t}), \omega(t), u(t) ; \\
u(t)=\sum_{i=1}^{3} U_{i}(\xi(t), y(t)),
\end{gathered}
$$

where $i$ is the order of the forms $G_{i}$ and $U_{i}$.

The synthesis of the regulator (28) is reduced to determining the matrix of the forms of the regulator gain $U_{i}$ by minimizing the norm of the target vector

$$
z(x(t), u(t), \eta(t))=\sum_{i=2}^{4} Z_{i}(x(t), u(t), \eta(t))
$$

on control vector of $u(t)$ and maximization of the same norm on a of plant uncertain vector $\eta(t)$ for the worst case disturbance.

The synthesis of the observer (27) is reduced [18] to determining the observer gain coefficients $G_{i}$ by minimization of the error vector of the recovery of the state vector $x(t)$ of the initial system (25) and maximization of the same norm of the error vector along the plant uncertainty vector $\eta(t)$ and the vector of external signal influences $\omega(t)$, which also corresponds to the worst case disturbance.

Matrices of the regulator $U_{i}$ and observer $G_{i}$ gain coefficients are found from approximate solutions of the Hamilton-Jacobi-Isaacs equations [18, 19], in which the matrices of linear forms being found from the four Riccati equations solutions. This approach corresponds to the standard 4-Riccati approach to the synthesis of linear robust or anisotropic regulators [19].

To determine the regulator (28) for plant (25) with target vector (29) consider Hamiltonian function

$$
\begin{aligned}
& H(x(t), u(t), \eta(t))=+V_{x}^{T}(x(t), u(t), \eta(t)) f(x(t), \ldots \\
& \ldots u(t), \eta(t))+z^{T}(x(t), u(t), \eta(t)) z(x(t), u(t), \eta(t))-\ldots \\
& -\frac{1}{\gamma^{2}} \eta^{T}(t) \eta(t),
\end{aligned}
$$

here $V_{x}$ are partial derivatives with respect to the state vector $x(t)$ of the infinite-horizon performance functional (Lyapunov function), $\gamma$ - weighting coefficient which determines the conservatism degree of the synthesized robust regulator

To determine the robust regulator (28) it is necessary to find the minimum norm of the target vector (29) along the control vector $u_{k}$ and the maximum of this norm along the external perturbations vector $\eta_{k}$, which reduces to solving the minimax extremal problem of Hamiltonian function [16] 


$$
H^{*}(x(t))=\min _{u(t) \eta(t)} \max _{\eta(t)}\{H(x(t), u(t), \eta(t))\} .
$$

The necessary conditions for the extremum of the Hamiltonian function (31) both in the control vector $u_{k}$ and in the external perturbation vector $\eta_{k}$ are these equations

$$
\begin{gathered}
H_{u}\left(x(t), u^{*}(x(t)), \eta^{*}(x(t))\right)=0 ; \\
H_{\eta}\left(x(t), u^{*}(x(t)), \eta^{*}(x(t))\right)=0,
\end{gathered}
$$

which are Hamilton-Jacobi-Isaacs equations. Here $H_{u}$ and $H_{\eta}$ are the partial derivatives of the Hamiltonian function with respect to the control vector $u(t)$ and with respect to the external perturbations vector $\eta(t)$.

Note that these equations (32), (33) are also necessary conditions for optimizing a dynamic game, in which the first player - the regulator which minimizes the target vector, and the second player - external disturbances which maximizes the same target vector.

The difficulty of obtaining a nonlinear control law is due to the fact that the difference Hamilton-Jacobi-Isaacs equations (32), (33) is a nonlinear partial differential equation. In this paper we use an approximate solution of the Hamilton-Jacobi-Isaacs equation (32), (33) assuming the analytical dependences of the nonlinearities of the original system (25), (26), (29) in the form of the corresponding series [19]. Then the linear approximation of the Hamilton-Jacobi-Isaac equation (32), (33) are the algebraic Riccati equations

$$
A^{T} P+P A+P\left[\frac{1}{\gamma^{2}} B_{\eta} B_{\eta}^{T}-B_{u} B_{u}^{T}\right] P+C_{z}^{T} C_{z}=0,
$$

here, the matrices $A, B_{\eta}, B_{u}, C_{z}$ in (34) are the corresponding matrices of the linear system obtained by linearizing the original nonlinear system (25), (26), (29).

Similarly matrices of the observer $G_{i}$ gain coefficients (27) are found from approximate solutions of the Hamilton-Jacobi-Isaacs equations [18].

Feed forward control synthesis. When the tank was moving, the error of the stabilization system of tank armaments was caused by the action of disturbance torques $T_{D G}(t), T_{D T}(t)$ that acts on the turret in the azimuth axis and on the gun in elevation axis from the side of the tank hull. Sensors that measure the hull angular position, hull angular rate, hull acceleration, etc in elevation and azimuth axes are mounted on the tank hull. These sensors can be used to observer disturbance torques $T_{D G}(t), T_{D T}(t)$ and their derivatives and implement open-loop control to improve the accuracy of the tank weapon stabilization systems when firing on the move. We introduce the state vectors $x_{d G}(t), x_{d T}(t)$ of the of external perturbation models, the components of which is the disturbance torques $T_{D G}(t), T_{D T}(t)$ that acts on the turret in the azimuth axis and on the gun in elevation axis and its derivatives. We write the mathematical models of external disturbances in the following form

$$
\begin{aligned}
& \frac{d x_{d G}(t)}{d t}=f_{d G}\left(x_{d G}(t), \omega_{d G}(t), \eta_{d G}(t)\right) ; \\
& \frac{d x_{d T}(t)}{d t}=f_{d T}\left(x_{d T}(t), \omega_{d T}(t), \eta_{d T}(t)\right),
\end{aligned}
$$

where $\omega_{d G}(t), \omega_{d T}(t), \eta_{d G}(t), \eta_{d T}(t)$ are the vectors of the external signal and parametric perturbations [7, 8], $f_{d G}, f_{d T}$ - are a nonlinear functions.

To realize the quasi invariant feed forward control by these disturbance torques $T_{D G}(t), T_{D T}(t)$ in the plant model (25) also introduced the external disturbance models (35), (36).

Then with the help of the observer (27) the external disturbances torques $T_{D G}(t), T_{D T}(t)$ and its derivatives also are observed [20] by measurement signals (26). Then the quasi-invariant feed forward control by external disturbances (35), (36) realize in form (28) by observer external disturbance state variables (27).

Multiobjective synthesis of nonlinear robust control. For tank main armament guidance and stabilization systems sufficiently stringent requirements are set for the performance indicators in various modes. In the guidance mode it is necessary to control by the gun rate and turret rate. In the stabilization mode it is necessary to control by the gun position and turret position. We bring a part of such performance indicators $[7,8]$. Time of working out of a given angle of error. Acceleration time to rated speed and deceleration time to full stop. An error in working out a harmonic signal of a specified amplitude and frequency. Stabilization error when moving along a normalized path with a random profile change with a given speed. Maximum speed of guidance. Minimum speed of guidance. Failure of guidance at minimum speed. Naturally, this should take into account the voltage and current limitations of the anchor chain of the drive motor, as well as the speed of rotation of the drive motor.

Dynamic characteristics of synthesized system including a nonlinear plant (25) that is closed by a robust controller (26), (27) are determined by the control system model of the system (25), the parameters of the measuring devices (26) and the target vector (29). For the correct definition of the target vector (29), we introduce the vector of the unknown parameters $\chi=\left\{Z_{i}\left(x_{k}, u_{k}, \eta_{k}\right)\right\}$, the components of which are the required weight matrices of the norm $Z_{i}\left(x_{k}, u_{k}, \eta_{k}\right)$. We introduce the vector of the objective function

$$
F(\chi)=\left[F_{1}(\chi), F_{2}(\chi) \ldots F_{m}(\chi)\right]^{T},
$$

in which the components $F_{i}(\chi)$ are direct quality indicators that are presented to the system in various modes of its operation such as the time of the first coordination, the time of regulation, overshooting, etc [7, 8].

To calculate the vectors objective function (37) and constraints on state variables and control, the initial nonlinear system (25), (26) is modeled by a closed synthesized nonlinear regulator (27), (28) in various modes of operation, with different input signals and for various values of the plant parameters [8]. This (37) multiobjective nonlinear programming problem [22, 23] is solved on the basis of multi-swarm stochastic multiagent optimization algorithms from Pareto optimal solutions [22, 23].

Computer simulation results. Comprehensive research of dynamic characteristics and sensitivity to the plant parameters change of the electromechanical tank armament stabilization systems with synchronous motor 
with permanent magnets taking into account the gun barrel elastic oscillations as a discrete-continuous plant with parametric uncertainty [8] with synthesized nonlinear robust regulators were conducted. As an example Fig. 1 shows state variables random processes implementation of the synthesized electromechanical tank gun stabilization systems in the elevation axis when the tank moves at a speed of $8 \mathrm{~m} \cdot \mathrm{s}^{-1}$ along a standard tank route. On Fig. 1 shows such state variables of a closed system: $a$ ) the angle $\varphi(t)$ of deviation between the axis of the object and the given direction, and $b$ ) its derivative $d \varphi(t) / d t ; c)$ the value of the function $W_{0 G}(t)$ in the representation $y_{G}(x, t)$ of the function, which characterizes the deviation of the tank barrel axis points from its state in the elevation axis, which is not deformed, and $d$ ) actuator torque $T_{A G}(t)$.
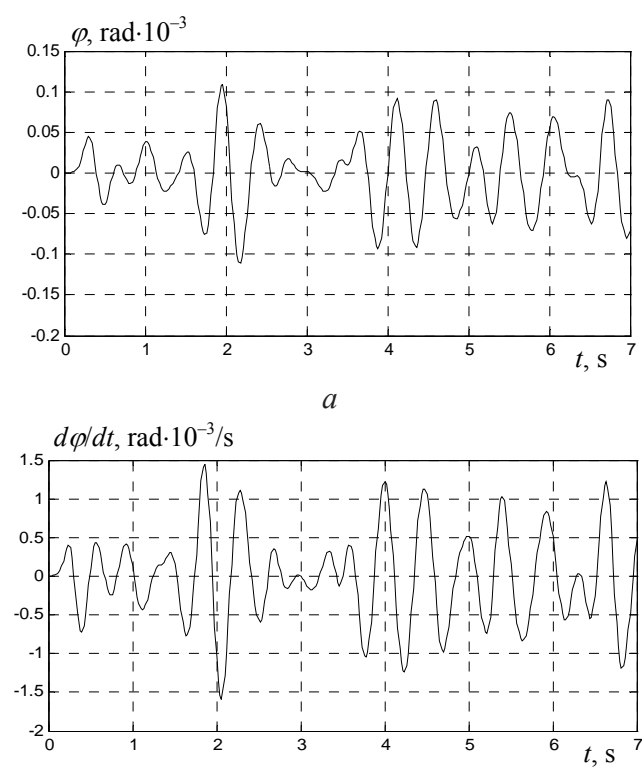

b

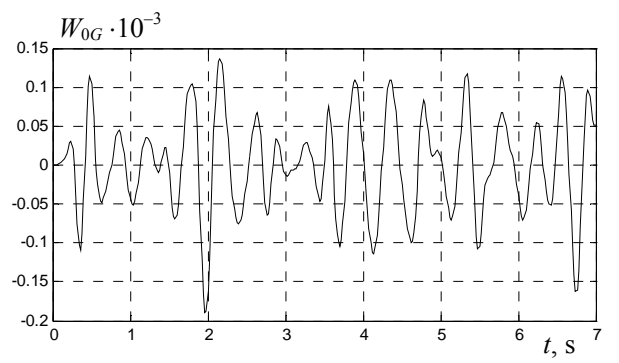

$c$

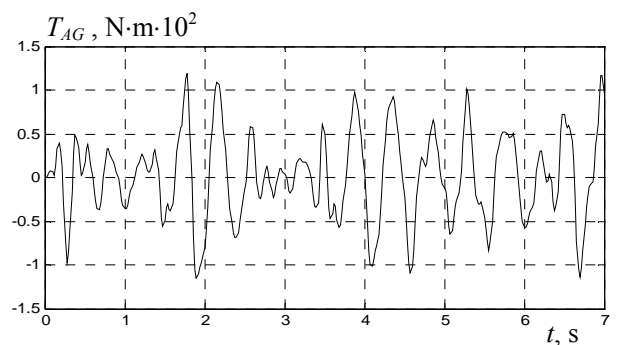

$d$

Fig. 1. State variables random processes implementation of the synthesized electromechanical tank gun stabilization systems in the elevation axis

As can be seen from Fig. 1.d, the actuator torques $T_{A G}(t)$ acting on the gun reaches $100 \mathrm{~N} \cdot \mathrm{m}$. The magnitude of disturbance torques $T_{D G}(t)$ acting on the gun, depends on the tank speed and the quality of the road surface. When moving along a mid-intersected area, these disturbance torques $T_{D G}(t)$ reach values $800 \mathrm{~N} \cdot \mathrm{m}$ [8]. With an increase the tank movement speed, the action of external disturbances gun weakens. This is explained by the fact that in the 4-6 $\mathrm{m} \cdot \mathrm{s}^{-1}$ movement speeds range, the resonant properties of the tank training system are manifested, and at speeds exceeding $8 \mathrm{~m} \cdot \mathrm{s}^{-1}$, the tank overcomes small effects, almost not responding to them. At the same time, with increased of the tank movement speed, the average frequency of oscillations of the function $F_{0 G}(x, t)$ in (19) significantly increases, which reduces the accuracy of aimed shooting on the move.

As can be seen from this figure, the error of stabilization of a given angle of a tank gun is about $0.1 \mathrm{mrad}$, which is about 1.7 times less than the error of a system with a typical proportional-differential controller $[2,10]$ and corresponds to the «Leclerc» tank weapons stabilization system accuracy [10, 24].

During the simulation of the dynamic characteristics of the synthesized electromechanical tank armament stabilization systems, it was found that the use of nonlinear robust control made it possible to reduce the time spent on working out the initial angular mismatch of $0.1 \mathrm{rad}$ between guns and targets directions. When the plant inertia moment was changed by $30 \%$, the mining time was changed by less than $10 \%$ while maintaining the level of overregulation, while in the system with a typical regulator, the mining time was changed to $30 \%$ with a significant change in the system overshoot. Thus, the use of nonlinear robust controllers also made it possible to reduce the sensitivity of the system to changes in the parameters of the control object as compared to the existing system.

\section{Conclusions.}

1. For the first time the method of multiobjective synthesis of nonlinear robust control by electromechanical tank armament stabilization systems with synchronous motor with permanent magnets taking into account the gun barrel elastic oscillations as a discrete-continuous plant and tank turret imbalance and with parametric uncertainty is developed.

2. Synthesis of nonlinear robust regulators and nonlinear robust observers reduces to solving the system of Hamilton-Jacobi-Isaacs equations. Robust control target vector is determined by solving the multi criterion nonlinear programming problem in which the components of the vectors of the objective function are direct quality indicators that are presented to the system in various modes of its operation.

3. Based on the computer model dynamic characteristics analysis of the synthesized electromechanical tank armament stabilization systems with synchronous motor with permanent magnets as a discrete-continuous plant shown that the use of synthesized nonlinear robust regulators made it possible to reduce by 1.7 times the error of stabilization of a given angular position of a tank gun when moving the tank, reduce by 1.8-2 times the time spent working off the initial angular misalignment of 
$0.1 \mathrm{rad}$ between the gun and target directions, reduce by $20 \%$ the system sensitivity to plant parameters changes in comparison with the existing system with standard proportional-differential regulator.

4. The results of the synthesis of electromechanical tank armament stabilization systems with synchronous motor with permanent magnets are recommended for use in the modernization of the T-64 tanks family.

\section{REFERENCES}

1. Chernyshev V.L., Tarasenko A.A., Ragulin S.V. Comparative evaluation of tactical and technical and structural parameters of T-64B tanks (BM «Bulat») and Leopard-2A4. Available at: http://btvt.narod.ru/raznoe/bulat-leo2.htm (accessed 05 May 2018). (Rus).

2. Koshelev V.V., Lavrishchev B.P., Sokolov V.Ya., Potemkin E.K., Prutkov V.N. Accuracy of complexes of tank-army armament according to military test data. Bulletin of armored vehicles, 1985, no.4, pp. 58-24. (Rus).

3. Features of the upgraded tanks T-64BV of Armed Forces of Ukraine. Available at: https://dianamihailova.livejournal.com/2524539.html (accessed 14 July 2018). (Rus).

4. M1 Abrams Main Battle Tank 1982-1992. New Vanguard 2. - Osprey Publishing (UC), 1993. 49 p.

5. Challenger 2 Main Battle Tank 1987-2006. New Vanguard 112. - Osprey Publishing (UC), 2006. 49 p.

6. Merkava - A History of Israel's Main Battle Tank. Marsh Gelbart. Tankograd Publishing-Vertag Jochen Vollert, Germany, 2005. 175 p.

7. Closed-loop optimization program for the M60A1 tank gun stabilization system. W. Binroth, Rock Island Arsenal, 1975. $251 \mathrm{p}$.

8. Aleksandrov E., Bogaenko I., Kuznetsov B. Parametric synthesis of tank weapon stabilization systems. Kyiv, Tehnika Publ., 1997. 112 p. (Rus).

9. All Electric Combat Vehicles (AECV) for Future Applications. Report of The Research and Technology Organization (RTO) of NATO Applied Vehicle Technology Panel (AVT) Task Group AVT-047 (WG-015), 2004. 234 p.

10. Eliseev A.D. Main directions of development of modern tank armament stabilizers. News of the Tula state university. Technical sciences, 2012, iss.11, part 2, pp. 3-9. (Rus).

11. Shamarih O.V. Electromechanical stablizers of tank armaments. Bulletin of armored vehicles, 1985, no.1, pp. 23-26.

12. Kozyrev V.V. Ways and prospects for improving the stabilizers of tank-water weapons. Defense equipment, 2005, no.2-3, pp. 65-71

13. Peresada S., Kovbasa S., Korol S., Zhelinskyi N. Feedback linearizing field-oriented control of induction generator: theory and experiments. Technical Electrodynamics, 2017, no.2, pp. 48-56. (Rus). doi: 10.15407/techned2017.02.048.

14. Buriakovskyi S., Maslii A., Maslii A. Determining parameters of electric drive of a sleeper-type turnout based on electromagnet and linear inductor electric motor. Eastern-European Journal of Enterprise Technologies, 2016, vol.4, no.1(82), pp. 32-41. (Rus). doi: $10.15587 / 1729-4061.2016 .75860$.
15. Rozov V.Yu., Reutskyi S.Yu., Pelevin D.Ye., Pyliugina $\mathrm{O} . \mathrm{Yu}$. The magnetic field of transmission lines and the methods of its mitigation to a safe level. Technical Electrodynamics, 2013, no. 2, pp. 3-9. (Rus).

16. William McEneaney M. Max-plus methods for nonlinear control and estimation. BirkhaËuser Boston Basel Berlin, 2006. $256 \mathrm{p}$.

17. Wilson Rugh J. Nonlinear System Theory. The Volterra. Wiener Approach. The Johns Hopkins University Press, 2002. $330 \mathrm{p}$.

18. Tolochko O. Analysis of observed-based control systems with unmeasured disturbance. 2017 IEEE First Ukraine Conference on Electrical and Computer Engineering (UKRCON), May 2017. doi: 10.1109/ukrcon.2017.8100402.

19. Kuznetsov B.I., Nikitina T.B., Tatarchenko M.O., Khomenko V.V. Multicriterion anisotropic regulators synthesis by multimass electromechanical systems. Technical Electrodynamics, 2014, no.4, pp. 105-107. (Rus).

20. Galchenko V.Ya., Yakimov A.N. A Turmitobionic Method for the Solution of Magnetic Defectometry Problems in Structural-Parametric Optimization Formulation. Russian Journal of Nondestructive Testing, 2014, vol.50, no.2, pp. 5971. doi: $10.1134 / \mathbf{s} 106183091402003 x$.

21. Xin-She Yang, Cui Zhihua, Xiao Renbin, Amir Hossein Gandomi, Mehmet Karamanoglu. Swarm Intelligence and BioInspired Computation: Theory and Applications. Elsevier Inc., 2013. 450 p. doi: 10.1016/C2012-0-02754-8.

22. Gal'chenko V.Y., Yakimov A.N., Ostapushchenko D.L. Pareto-optimal parametric synthesis of axisymmetric magnetic systems with allowance for nonlinear properties of the ferromagnet. Technical Physics, 2012, vol.57, no.7, pp. 893899. doi: 10.1134/s1063784212070110.

23. Shoham Y., Leyton-Brown K. Multiagent Systems: Algorithmic, Game-Theoretic, and Logical Foundations. Cambridge University Press, 2009. 504 p. doi: 10.1017/CBO9780511811654.

24. Gun turret drives: Electric stabilization systems for military ground vehicles. Available at: https://www.jenoptik.com/products/defense-and-

security/stabilization-systems/gun-turret-drives (accessed 11 August 2018).

Received 27.11.2018

B.I. Kuznetsov ${ }^{1}$, Doctor of Technical Science, Professor,

T.B. Nikitina ${ }^{2}$, Doctor of Technical Science, Professor,

I.V. Bovdui ${ }^{1}$, Candidate of Technical Science,

B.B. Kobilyanskiy ${ }^{1}$, Candidate of Technical Science, Associate

Professor,

${ }^{1}$ State Institution «Institute of Technical Problems of Magnetism of the NAS of Ukraine»,

19, Industrialna Str., Kharkiv, 61106, Ukraine, phone +380505766900 ,

e-mail: kuznetsov.boris.i@gmail.com

${ }^{2}$ Kharkov National Automobile and Highway University, 25, Yaroslava Mudroho Str., Kharkov, 61002, Ukraine, e-mail: tatjana55555@gmail.com 